\title{
REMOÇÃO DO ÓLEO DA ÁGUA PRODUZIDA SINTÉTICA UTILIZANDO BAGAÇO DE CANA-DE-AÇÚCAR COMO ADSORVENTE
}

\author{
E. M. de PAIVA, R. R. MAGALHÃES, E. P. dos SANTOS, A. I. C. GARNICA e F. D. da \\ SILVA CURBELO
}

Universidade Federal da Paraíba, Departamento de Engenharia Química

E-mail para contato: evanice.medeiros@hotmail.com

\begin{abstract}
RESUMO - Na produção de um poço de petróleo, não apenas óleo e gás são produzidos, mas também a água. Gotículas de óleo encontram-se dispersas na água produzida sob as formas livre, dissolvida e emulsionada, o que inviabiliza o seu descarte, reuso e injeção. Por este motivo a busca crescente por tratamentos alternativos desse efluente tem estimulado diversas áreas de pesquisa. $\mathrm{O}$ processo de adsorção tem aparecido como uma técnica de grande potencial para o tratamento de efluentes industriais, devido ao emprego de resíduos como adsorvente. A disponibilidade, o baixo custo e a não agressão ao meio ambiente torna a biomassa um adsorvente emergente. O bagaço da cana-de-açúcar foi empregado como adsorvente para remoção de óleo emulsionado na água produzida sintética. Neste estudo avaliou-se a capacidade adsortiva, através de ensaios onde variava-se as concentrações de óleo em água produzida, mantendo massas fixas de adsorvente. Os resultados mostraram que os dados experimentais foram bem representados pelos modelos de Adsorção de Langmuir e Freundlich. Entretanto, o primeiro modelo mostrou-se um pouco mais significativo nas análises estatísticas, caracterizando a adsorção em monocamada.
\end{abstract}

\section{INTRODUÇÃO}

O aumento de resíduos resultantes dos processos industriais tem agravado os impactos negativos ao meio ambiente. Dessa forma, a preocupação com a manutenção do ecossistema juntamente com as legislações vigentes tem exigido das empresas maiores investimentos quanto ao gerenciamento dos seus efluentes.

A indústria petrolífera apresenta uma grande importância no cenário econômico mundial, entretanto, suas atividades de produção e exploração geram resíduos e efluentes. $\mathrm{O}$ petróleo e o gás natural são misturas de hidrocarbonetos resultantes de processos físicoquímicos sofridos pela matéria orgânica durante a formação de bacias sedimentares, há milhões de anos (Curbelo, 2002).

Na etapa de exploração de um poço de petróleo, além da elevação do petróleo e gás, a água presente nas formações também é trazida à superfície. As alternativas usualmente adotadas para o destino da água produzida são o descarte, a injeção e o reuso. Em todos os casos, há necessidade de tratamento específico a fim de atender as demandas ambientais, operacionais ou da atividade produtiva que a utilizará como insumo. Um dos objetivos do 
tratamento é a remoção de óleo, que pode estar presente na água sob as formas livre, em emulsão (ou emulsionada) e dissolvido (Motta, 2013). No caso do descarte em corpos receptores o limite é de até $20 \mathrm{mg} / \mathrm{L}$ de teor de óleo e graxas (TOG) na água produzida, segundo a Resolução 357/2005 do Conselho Nacional de Meio Ambiente (CONAMA). Para o descarte em plataformas marítimas de petróleo, aplica-se a Resolução 393/2007 do CONAMA, que estabelece a média aritmética simples mensal de teor de óleos e graxas de até $29 \mathrm{mg} / \mathrm{L}$, com valor máximo diário de $42 \mathrm{mg} / \mathrm{L}$ (CONAMA, 2014). Para injeção em poços de petróleo água deverá ter no máximo $5 \mathrm{mg} / \mathrm{L}$ de TOG (Gomes, 2009).

Nos últimos anos, o processo de adsorção tem aparecido como uma técnica de grande potencial para o tratamento de efluentes industriais, principalmente devido à utilização de adsorventes naturais onde alguns são obtidos de subprodutos da indústria e da agricultura. Como é o caso do bagaço da cana, resíduo sólido que remanesce da moagem da cana-deaçúcar nas usinas sucroalcooleiras. Diversos países, inclusive o Brasil, realizam pesquisas sobre a reciclagem desse resíduo como matéria-prima alternativa nos diversos setores industriais, tendo em vista a preservação do meio ambiente (Souza et al., 2009).

Este trabalho estudou a utilização do bagaço de cana-de-açúcar, como adsorvente, na remoção do óleo presente nas soluções que reproduzem a concentração de águas produzidas nas indústrias petrolíferas. Os resultados gerados serviram para avaliar a viabilidade deste processo.

\section{METODOLOGIA}

\subsection{Preparação do Adsorvente}

O bagaço de cana-de-açúcar foi lavado em água corrente para remoção de possíveis materiais indesejáveis, como: pedaço de palha, areia ou madeira que poderiam causar interferências nos resultados experimentais. O material foi colocado em estufa SL - 102 com circulação e renovação de ar à $60^{\circ} \mathrm{C}$ por, aproximadamente, $40 \mathrm{~h}$ para remoção de umidade. Para um diâmetro médio de partículas entre 0,5 e $2 \mathrm{~mm}$, o bagaço foi moído utilizando-se um moinho de facas SL - 31e peneirado utilizando-se uma sequência de peneiras da série de Tyler de malhas $-9+28 \#$.

\subsection{Sintetização da Água Produzida}

Para cada litro de água destilada, foram adicionados $35 \mathrm{~g}$ de $\mathrm{NaCl}$ e aproximadamente, $2,0 \mathrm{~g}$ de óleo. Neste caso, a fase oleosa foi o querosene. As emulsões óleo/água sintéticas foram geradas empregando-se o Dispersor Extratur Quimis Q252 28, a uma rotação de 12.000 rpm em um período de 15 minutos. A partir desta solução, diluições foram realizadas a fim de se obter diferentes concentrações para água produzida.

\subsection{Ensaio em Banho Finito}


Foram realizados dois ensaios à temperatura ambiente (aproximadamente $30^{\circ} \mathrm{C}$ ) utilizando massas de adsorventes de 0,5 e $2,5 \mathrm{~g}$, e um volume de $120 \mathrm{~mL}$ de água produzida no Banho Metabólico Dubnoff a 37,5 rpm. O tempo de equilíbrio estipulado foi de $6 \mathrm{~h}$.

\subsection{Separação e Determinação do Teor de Óleo: Método do clorofórmio}

O método do clorofórmio foi empregado para separação do óleo não adsorvido. Curbelo (2002) propôs o seguinte: coletar $100 \mathrm{~mL}$ de amostra; adicionar $10 \mathrm{~mL}$ de solvente (clorofórmio); agitar por 5 minutos; coletar a fase solvente após separação de fases; centrifugar a fase solvente durante 2 minutos; ler a absorbância em $260 \mathrm{~nm}$ no espectrofotômetro; determinar a concentração do óleo através da curva de calibração.

\subsection{Ajuste dos Dados de Equilíbrio aos Modelos de Adsorção (Langmuir e Freundlich)}

Através do balanço de massa (Equação 1), calculou-se a massa de óleo adsorvida no bagaço da cana.

$$
q=\frac{V\left(C_{\text {iniciall }}-C_{\text {final }}\right)}{m} \quad\left[\frac{m g \text { de óleo }}{g \text { de bagaço }}\right]
$$

Em que, $V$ é o volume da solução, $\mathrm{C}_{\text {inicial }}$ e $\mathrm{C}_{\text {final }}$ são, respectivamente, as concentrações inicial e final do óleo na solução, $m$ é a massa de adsorvente e q representa os miligramas de óleo adsorvido por grama de bagaço.

O ajuste dos dados experimentais ao modelo de Langmuir foi feito pela Equação 2.

$$
q=\frac{b q_{m} C_{e}}{1+b C_{e}}
$$

Em que, q é a quantidade de soluto adsorvida por unidade de massa de adsorvente; $\mathrm{q}_{\mathrm{m}} \mathrm{a}$ quantidade máxima de soluto que pode ser adsorvida; b a constante relacionada com a energia de adsorção soluto-superfície adsorvente; e Cea concentração de equilíbrio.

A isoterma do modelo de Freundlich, é dada pela Equação 3.

$$
q=K C_{e}^{1 / n}
$$

Em que, K é a constante de Freundlich referente à capacidade da adsorção; e n é o expoente de Freundlich referente a eficiência do processo de adsorção.

\section{RESULTADOS E DISCUSSÃO}


A Figura 1 apresenta os dados experimentais de adsorção do óleo no bagaço da cana-deaçúcar. Observa-se que a isoterma de adsorção, quando a massa de adsorvente utilizada foi de 0,5g (menor quantidade de adsorvente), apresentou resultados melhores na adsorção do óleo. Este comportamento pode ser explicado devido ao fato que foi observado que uma massa maior de adsorvente produzia uma interação menor com solução a ser tratada, pois uma quantidade considerável do adsorvente ficava sobrenadando na superfície da solução, dificultando o contato entre as fases e consequentemente influenciando o rendimento no processo de adsorção. Provavelmente um sistema de agitação mais eficiente poderia solucionar este problema.

Figura 1 - Isotermas de adsorção.

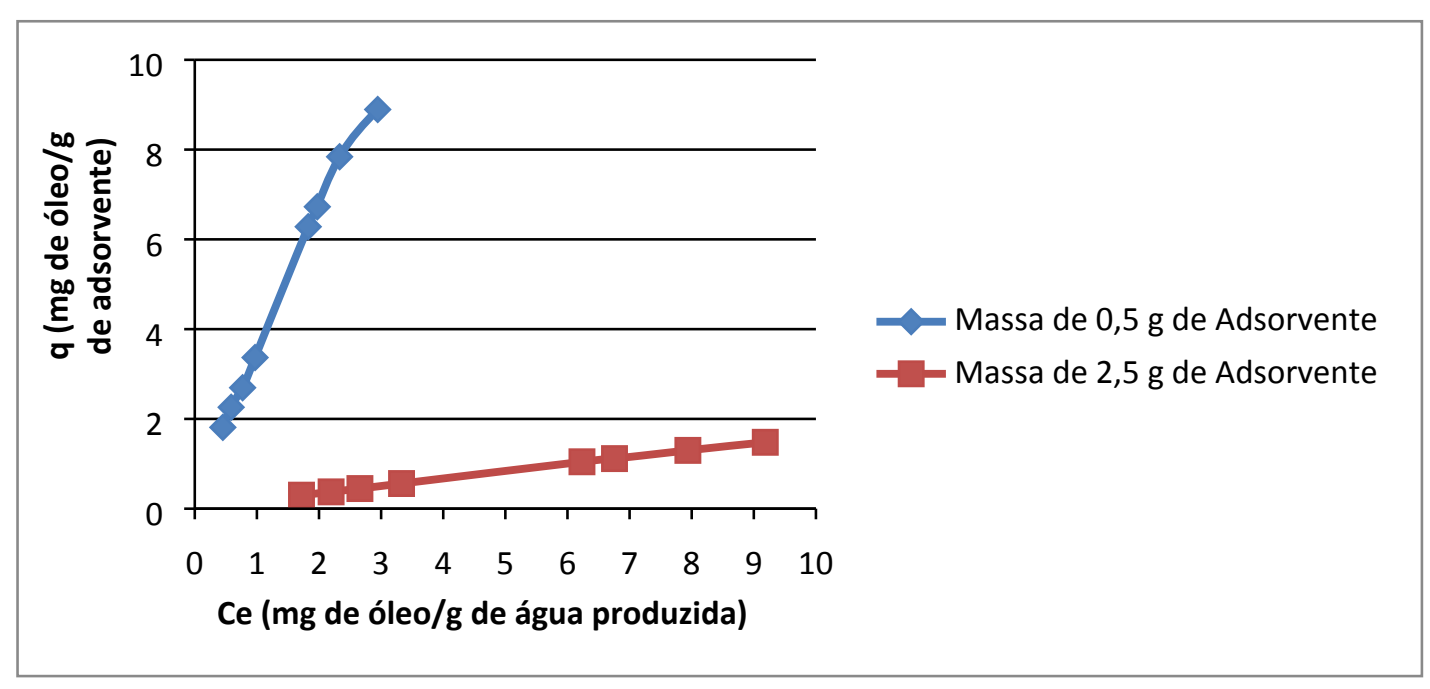

Os dados foram tratados utilizando o método da regressão não linear, e foram determinados os parâmetros dos modelos de Langmuir e Freundlich (Tabela 1).

Tabela 1 - Parâmetros das isotermas de Langmuir e Freundlich

\begin{tabular}{|c|c|c|c|}
\hline \multirow{2}{*}{ Isoterma } & Parâmetros & $\begin{array}{c}\text { Massa de 0,5 g de } \\
\text { adsorvente }\end{array}$ & $\begin{array}{c}\text { Massa de 2,5 g de } \\
\text { adsorvente }\end{array}$ \\
\hline \multirow{3}{*}{ Langmuir } & $\mathbf{b}$ & 0,10423 & 0,00927 \\
\cline { 2 - 4 } & $\mathbf{q}_{\mathbf{m}}$ & 38,80832 & 18,9247 \\
\cline { 2 - 4 } & $\mathbf{R}^{\mathbf{2}}$ & 0,996 & 0,999 \\
\hline \multirow{3}{*}{ Freundlich } & $\mathbf{K}$ & 3,624951 & 0,178774 \\
\cline { 2 - 4 } & $\mathbf{1} / \mathbf{n}$ & 0,87 & 0,96 \\
\cline { 2 - 4 } & $\mathbf{R}^{\mathbf{2}}$ & 0,993 & 0,999 \\
\hline
\end{tabular}

Os dados da tabela 1 mostram como a adsorção para uma massa menor de adsorvente foi melhor em ambos os modelos. Isto pode ser observado para o modelo de Langmuir através do parâmetro $\mathrm{q}_{\mathrm{m}}$ que indica a adsorção máxima e no modelo de Freundlich através do parâmetro $1 / \mathrm{n}$ que indica a facilidade com que o processo de adsorção se verifica. Comparando os dos modelos o de Langmuir se ajustou melhor aos dados experimentais já que 
no modelo de Freundlich o parâmetro $1 / \mathrm{n}$ ficou entre $0,5<1 / \mathrm{n}<1$, que neste caso conduz a uma adsorção razoável (Samiey e Dargahi, 2010).

As Figuras 2 e 3 mostram o ajuste do modelo de Langmuir para as duas massas de adsorvente utilizadas. Nestas podem-se verificar a adequação favorável do modelo de Langmuir aos dados experimentais.

Figura 2 - Modelo de Langmuir para a massa de adsorvente de 0,5 g.

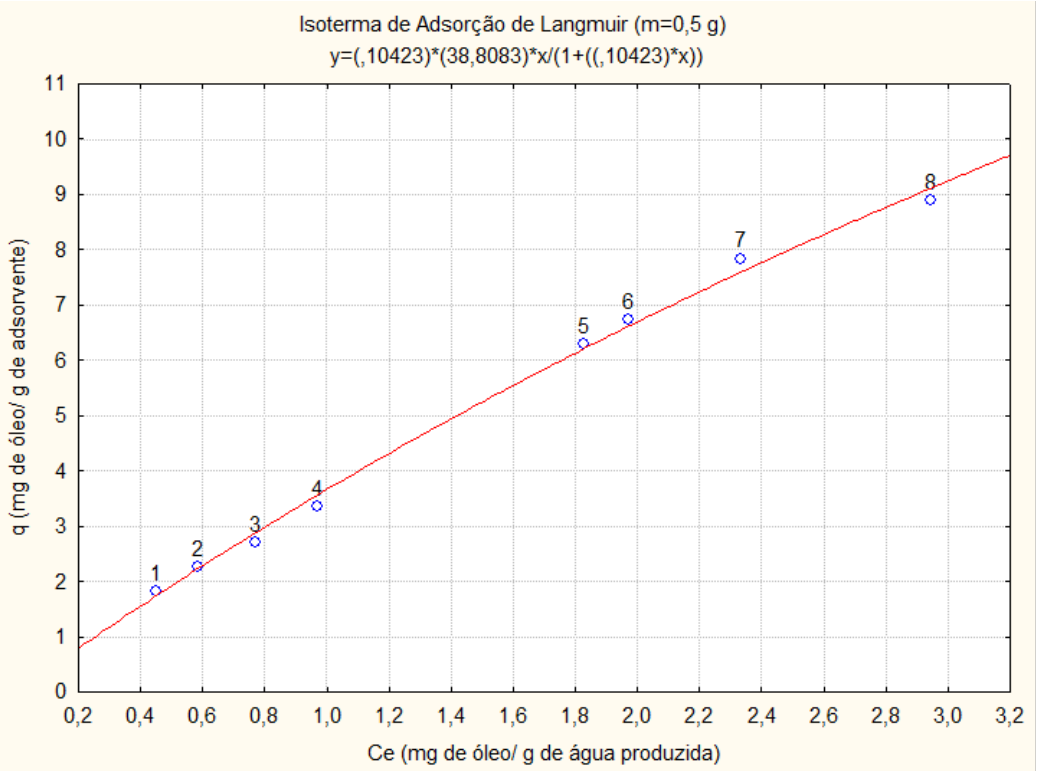

Figura 3 - Modelo de Langmuir para a massa de adsorvente de 2,5 g.

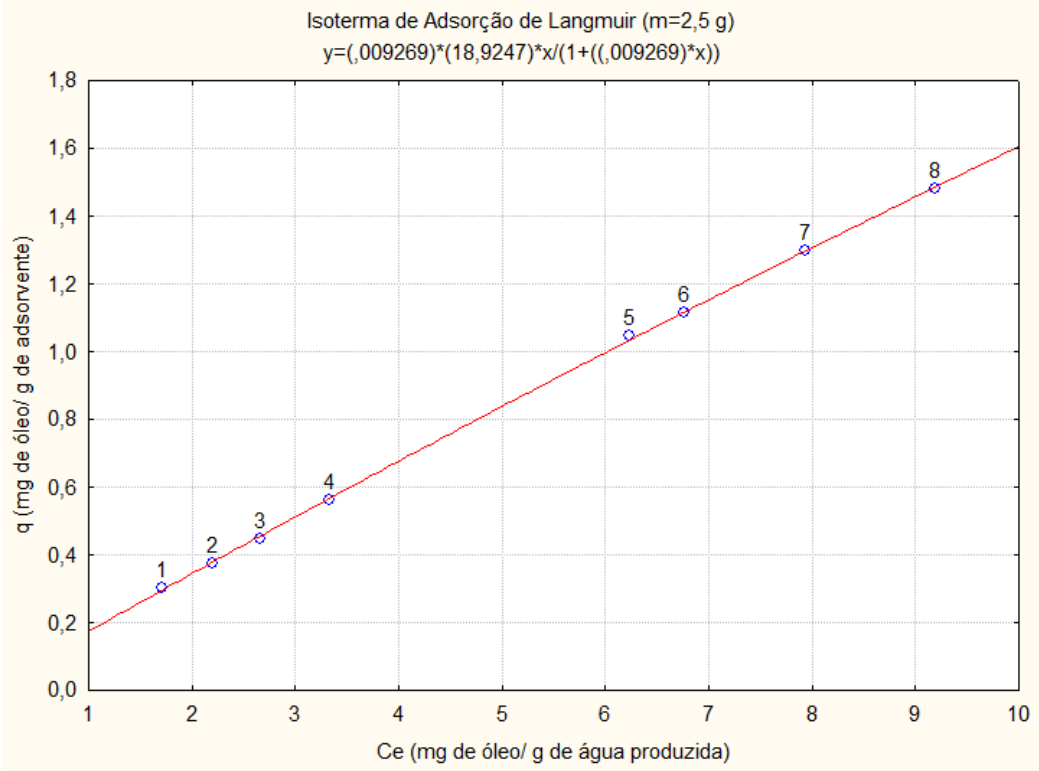

\section{CONCLUSÃO}


O estudo mostra que o bagaço de cana de açúcar, in natura, é um bom adsorvente na remoção de óleo da água produzida sintética. $\mathrm{O}$ modelo de Langmuir se ajustou mais adequadamente aos dados experimentais, caracterizando uma adsorção em monocamada.

\section{REFERÊNCIAS}

CAVALCANTE Jr., C. L., Separação de misturas por adsorção: dos fundamentos ao processo em escala comercial. Tese submetida ao concurso público para professor titular, Universidade Federal do Ceará, Fortaleza: DEQ, 1998.

CONAMA, disponível em: www.mma.gov.br/port/conama/legipesq. Consultado em $15 / 11 / 2014$.

CURBELO, Fabíola Dias da SILVA - Estudo da remoção de óleo em águas produzidas na indústria de petróleo, por adsorção em coluna utilizando a vermiculita expandida e hidrofobizada. Dissertação de Mestrado, UFRN, Programa de Pós-graduação em Engenharia Química, Natal - RN, Brasil.

GOMES, E. A. Tratamento combina da água produzida do petróleo por eletroflotação e processo Fenton. Dissertação de Mestrado, UNIT, PEP, 2009.

MOTTA, A. R. P.; BORGES, C. P.; KIPERSTOK, A.; ESQUERRE, K. P.; ARAUJO, P. M.; BRANCO, L. P. N.; Tratamento de água produzida de petróleo para remoção de óleo por processos de separação por membranas: revisão. Eng Sanit Ambient, Salvador, v.18, n.1, p.15-26, 2013.

SAMIEY, B e DARGAHI, M, Kinets and Thermodynamics of adsorption of Congo red on cellulose, Central Eur. J. Chem. 8 (2010) 906-912.

SOUZA, R. S.; SANTOS, T. C.; LIMA, L, R. Reuso do Bagaço da Cana-de-açúcar em Tratamento de Efluentes Industriais através da Adsorção. I Congresso Paraibano de Gestão do Lixo, Educação Ambiental e Sustentabilidade. Campina Grande - PB. 2009. 